\title{
In vitro evaluation of the antioxidant capacity of molecular hybrids compounds of ditert-butylphenolic betacalcogenamine containing tellurium
}

\section{Giuliana P. Zugno ${ }^{1}$, Paloma T. Birmann ${ }^{1}$, Renata A. Balaguez ${ }^{2}$, Evelyn Terhaag ${ }^{2}$, Fábio Zazyki Galetto ${ }^{2}$ and Lucielli Savegnago ${ }^{1 *}$}

${ }^{1}$ Research Group on Neurobiotechnology - GPN, CDTec, Federal University of Pelotas, UFPel, Pelotas, RS, Brazil; giulizugno@gmail.com, paloma_birmann@hotmail.com and luciellisavegnago@yahoo.com.br

${ }^{2}$ Laboratory of Multicomponent Synthesis - LaSIMC, Federal University of Santa Catarina, UFSC, SC, Brazil; renata.balaguez@gmail.com, evelynterhaag@gmail.com, galettofz@gmail.com

* Correspondence: luciellisavegnago@yahoo.com.br

\section{INTRODUCTION}

Tellurium (Te) is a semimetal belonging to the chalcogen group. It can present itself under four different oxidation states, which grants its compounds excellent antioxidant activity. Given these properties, organotelered compounds arouse interest regarding their antioxidant activities to neutralize the overproduction of reactive species, which is a hallmark of a variety of human diseases.

In view of the importance of antioxidant defense mechanisms for neutralizing oxidative stress promoters, this study aimed to evaluate the in vitro antioxidant activity of molecular hybrids compounds of ditert-butylphenolic betacalcogenamine, referred as $\mathbf{5 f}$ and $\mathbf{5 h}$ (Figure 1 ).

\section{MATERIALS AND METHODS}

The compounds were synthesized by the Multicomponent Synthesis Laboratory, at the Federal University of Santa Catarina. For in vitro antioxidant analyzes, they were diluted in dimethyl sulfoxide (DMSO) on a concentration curve $(0.1 \mu \mathrm{M}-100 \mu \mathrm{M})$.

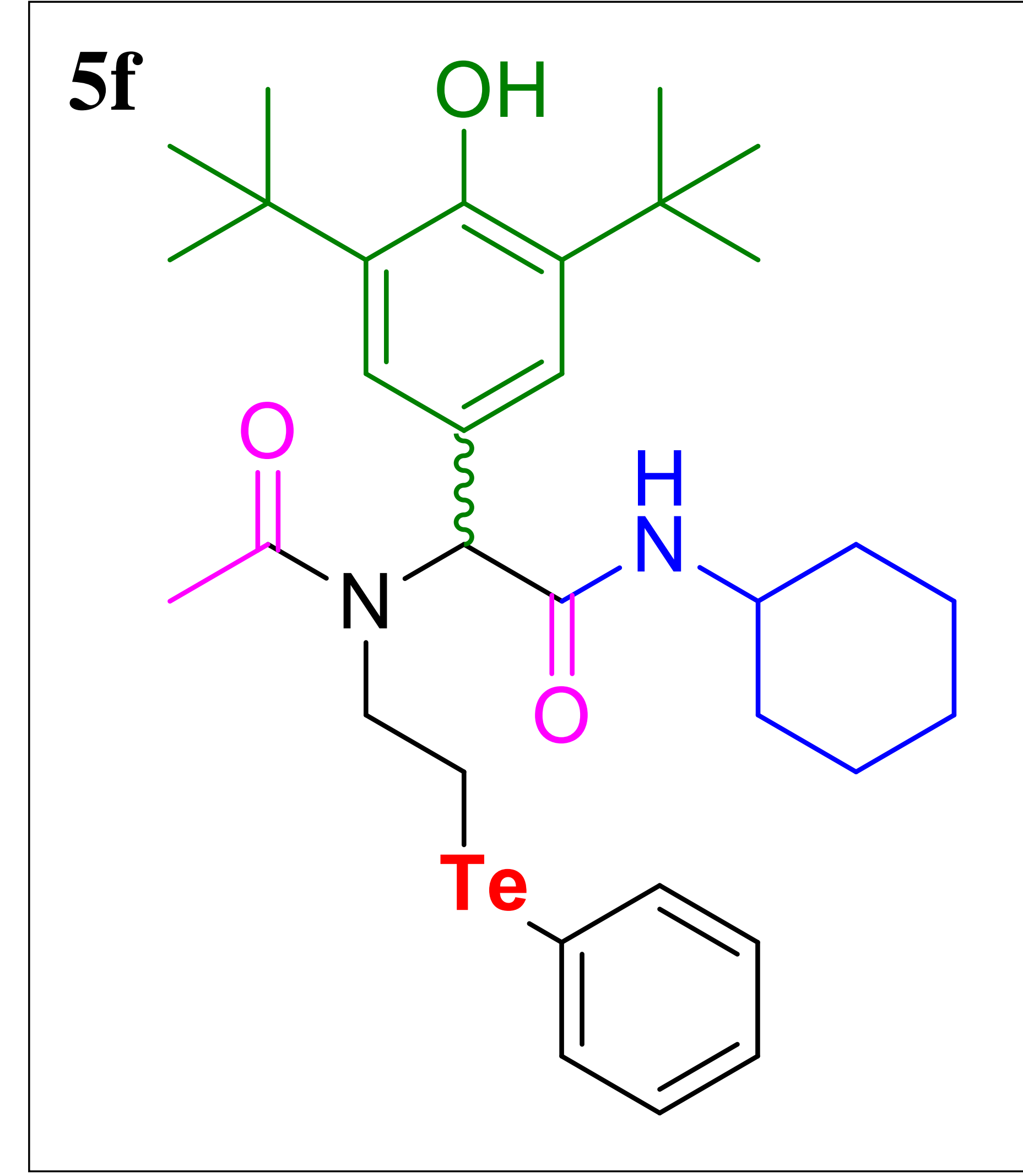

(a)

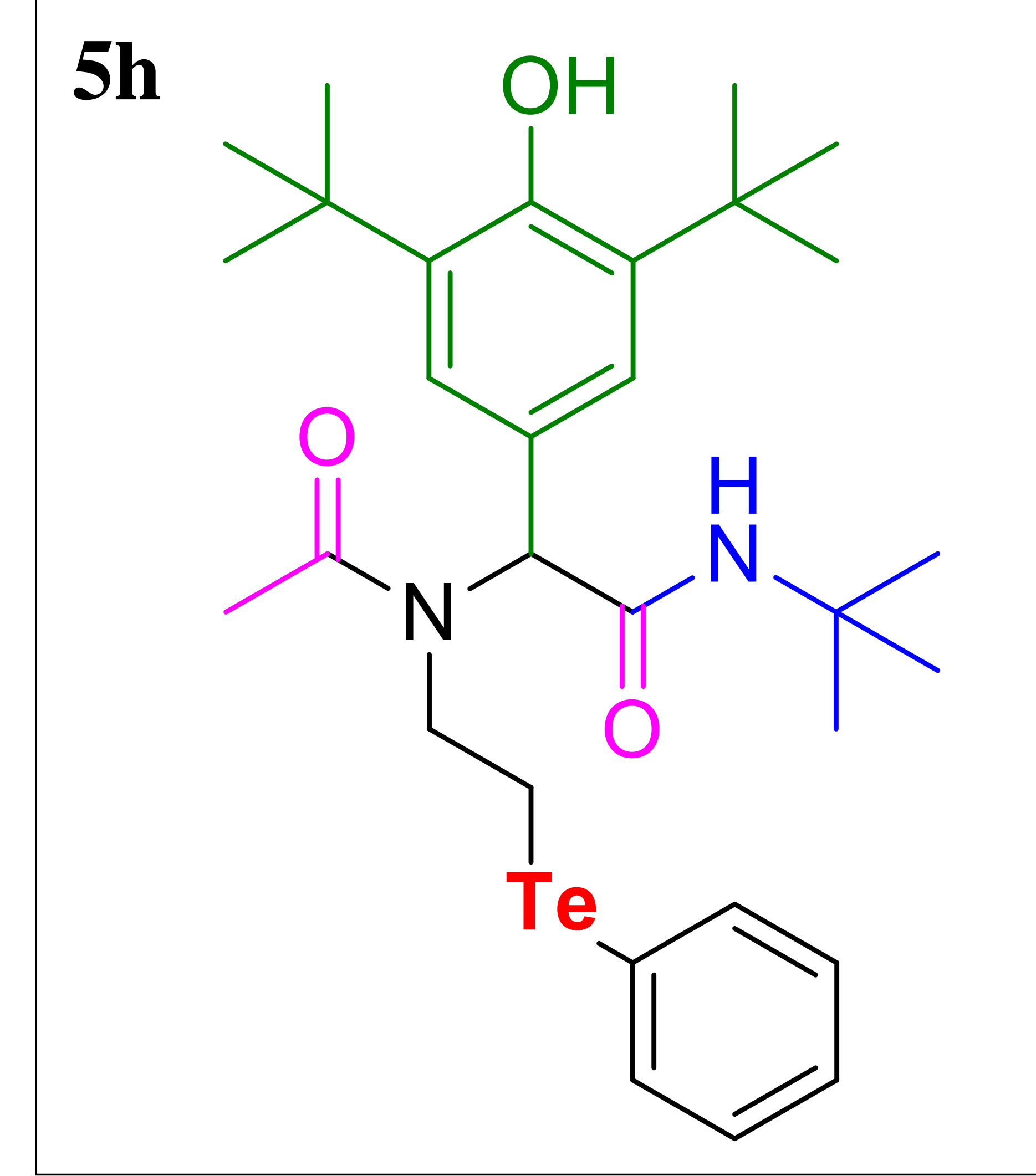

(b)
Figure 1. Chemical structures of the molecular hybrid compounds of di-tert-butylphenolic betacalcogenamine. (a) $\mathrm{N}$ - cyclohexyl - 2 - (3,5 - di - tert - butyl - 4 - hydroxyphenyl) - 2 - ( $\mathrm{N}$ (2 -(phenyltellanyl) ethyl) acetamido) acetamide; (b) N - (tert-butyl) - 2 -(3,5 - di - tert - butyl 4 - hydroxyphenyl) - 2 - (N - (2- (phenyltellanyl) ethyl) acetamido) acetamide.

The method for assessing antioxidant capacity via free radical scavenging activity 2,2-diphenyl-1-picryl-hydrazil $\left(\mathrm{DPPH}^{\bullet+}\right)$ was adapted from the method of Choi et al. and the antioxidant activity through the capture of 2,2'-azinobis (3ethylbenzothiazoline-6-sulfonic acid) radicals $\left(\mathrm{ABTS}^{+}\right)$, was determined as described by $\operatorname{Re}$ et al. with some adaptations. Furthermore, the ferric ion reducing antioxidant power (FRAP) assay was performed according to Stratil et al., with some modifications.

\section{RESULTS}

The results suggest that $\mathbf{5 f}$ was more potent in neutralizing $\mathrm{DPPH}^{\bullet+}$ radicals when compared to compound $5 \mathbf{h}$, although both presented the same radical scavenging efficiency. Nonetheless, compounds $\mathbf{5 f}$ and $\mathbf{5 h}$ showed the same potency when evaluated by the $\mathrm{ABTS}^{+}$method, however, 5f exhibit higher $\mathrm{ABTS}^{+}$radical scavenging efficiency. Additionally, $\mathbf{5 f}$ and $\mathbf{5 h}$ exhibited ferricreducing ability at a concentration of $10 \mu \mathrm{M}$, being the reduction power improved as the compound concentration increased (Figure 2).
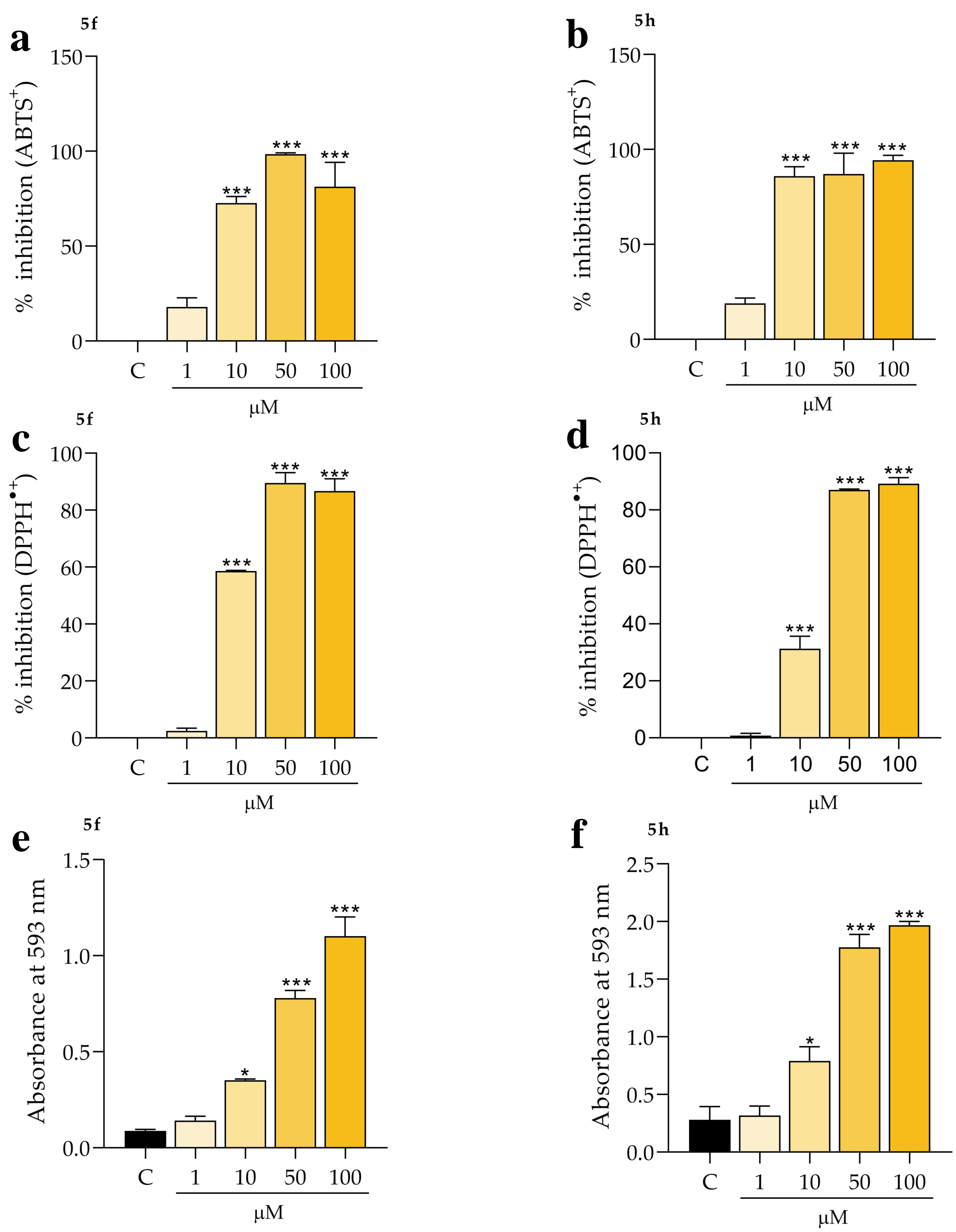

Figure 2. Values are presented as the percentage of inhibition of $\mathrm{ABTS}^{+}$radicals by $\mathbf{5 f}$ in $\mathbf{a}$ and $\mathbf{5 h}$ in $\mathbf{b}$; the percentage of inhibition of $\mathrm{DPPH}^{\bullet+}$ radicals by $5 \mathbf{f}$ in $\mathbf{c}$ and $5 \mathbf{h}$ in $\mathbf{d}$ and ferric ion reducing antioxidant power of $\mathbf{5} \mathbf{f}$ in $\mathbf{e}$ and $\mathbf{5 h}$ in $\mathbf{f}$. Data are presented as the mean \pm standard error of the mean $(\mathrm{SEM})(\mathrm{n}=3)$. The asterisks describe values levels of statistical significance $\left({ }^{*} p<0.05\right.$ and ${ }^{* *}$ $\mathrm{p}<0.001$ ) when compared to the control by one-way ANOVA followed by Tukey's post-hoc test.

\section{CONCLUSION}

In summary, these findings show that the molecular hybrid compounds of di-tert-butylphenolic betacalcogenamine containing tellurium are promising targets for future studies on their antioxidant potential for the treatment of pathophysiology related to oxidative impairment 